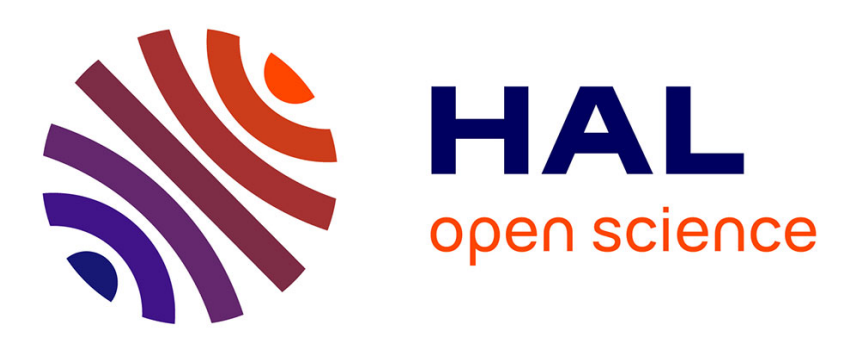

\title{
Typology of schizotypy in non-clinical young adults: Psychopathological and personality disorder traits correlates
}

Patrick Raynal, Nelly Goutaudier, Victoria Nidetch, Henri Chabrol

\section{- To cite this version:}

Patrick Raynal, Nelly Goutaudier, Victoria Nidetch, Henri Chabrol. Typology of schizotypy in nonclinical young adults: Psychopathological and personality disorder traits correlates. Psychiatry Research, 2016, 246, pp.182-187. 10.1016/j.psychres.2016.09.042 . hal-03193782

\section{HAL Id: hal-03193782 \\ https://hal.science/hal-03193782}

Submitted on 9 Apr 2021

HAL is a multi-disciplinary open access archive for the deposit and dissemination of scientific research documents, whether they are published or not. The documents may come from teaching and research institutions in France or abroad, or from public or private research centers.
L'archive ouverte pluridisciplinaire HAL, est destinée au dépôt et à la diffusion de documents scientifiques de niveau recherche, publiés ou non, émanant des établissements d'enseignement et de recherche français ou étrangers, des laboratoires publics ou privés. 
Typology of schizotypy in non-clinical young adults: Psychopathological and personality disorder traits correlates

\section{Patrick Raynal $^{\text {a*}}$, Nelly Goutaudier ${ }^{\mathrm{a}}$, Victoria Nidetch ${ }^{\mathrm{a}}$, Henri Chabrol $^{\mathrm{a}}$}

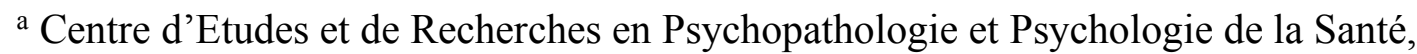
Université de Toulouse, UT2J, France

* Corresponding author: Dr. Patrick Raynal, Laboratoire CERPPS, Université de ToulouseJean Jaurès, 5 allées Antonio Machado, 31058 Toulouse, France. Phone number: 3356122 52 90. Fax number: 335612570 93. E-mail: patrick.raynal@inserm.fr 


\section{Abstract}

Few typological studies address schizotypy in young adults. Schizotypal traits were assessed on 466 college students using the Schizotypal Personality Questionnaire-Brief (SPQ-B). Other measures evaluated personality traits previously associated with schizotypy (borderline, obsessionnal, and autistic traits), psychopathological symptoms (suicidal ideations, depressive and obsessive-compulsive symptoms) and psychosocial functioning. A factor analysis was first performed on SPQ-B results, leading to four factors: negative schizotypy, positive schizotypy, social anxiety, and reference ideas. Based on these factors, a cluster analysis was conducted, which yielded four clearly distinct groups characterized by "Low" (non schizotypy), "High schizotypy" (mixed positive and negative), "Positive schizotypy", and "Social impairment". Regarding personality disorder traits and psychopathological symptoms, the "High schizotypy" cluster scored higher than the "Positive" and the "Social impairment" groups, which scored higher than the "Low" cluster. The "Positive" group had higher levels of interpersonal relationships than in the "High" and the "Social impairment" clusters, suggesting that positive schizotypy was associated to benefits such as perceived social relationships. Nevertheless the "Positive" cluster was also linked to high levels of personality disorder traits and psychopathological symptoms, and to low academic achievement, at levels similar those observed in the "Social impairment" cluster, confirming an unhealthy side to positive schizotypy.

Keywords: Personality disorder traits; Cluster analysis. 


\section{Introduction}

Symptoms of schizophrenia and schizotypy could be grouped in three dimensions: positive (unusual experiences, odd beliefs, and magical thinking), negative (anhedonia, apathy, social anxiety and social withdrawal) and disorganized (eccentricity, odd behavior and speech). Positive and negative dimensions were the most consistently replicated factors (Gross et al., 2015). Kocsis-Bogár et al. (2015) reported continuity between the positive and negative dimensions of schizotypy and positive and negative symptoms of schizophrenia, while Kwapil et al. (2013) reported that positive and negative schizotypy dimensions predicted schizophrenia-spectrum disorders.

Cluster analytic studies of schizotypy intend to identify distinct groups of individuals that could be associated differentially with psychopathology, impairment, and risk of developing schizophrenia-spectrum disorders or other disorders. While many variablecentered studies have been conducted, there is a lack of typological studies on schizotypy involving young adults. In 1994, Williams identified in a small sample of undergraduate students four clusters defined respectively by low schizotypy, ideational and perceptual features of schizotypy, physical anhedonia and social anxiety/cognitive disorganization (Williams 1994). More recently, four studies were conducted on large samples of adolescents or college students and three of them also forced a four-cluster solution. All of these three studies found a low (non-schizotypic) cluster and a high (mixed) schizotypy cluster characterized by high positive and negative schizotypy. However they differed on the remaining clusters. There were "average" and "positive/disorganized" (Suhr and Spitznagel, 2001); "high positive" and "high negative" (Barrantes-Vidal et al., 2003, 2010). The fourth study found a six-cluster solution: "low", "average", "high unusual experiences" (high positive), "high introvertive anhedonia" (high negative), and "high introvertive 
anhedonia/cognitive disorganization" (high negative/disorganized) (Tabak and Weisman de Mamani, 2013).

The most recent studies explored whether clusters differed on behavioral correlates other than schizotypic symptoms. Based on correlational studies, Barrantes-Vidal et al. (2010) compared clusters on history of depression, substance abuse, social adjustment and dimensions of the Five-Factor Model of personality: the positive schizotypy cluster had a history of depression and substance abuse, and was open to experience and extraverted; the negative schizotypy cluster had impaired social adjustment, high conscientiousness and low agreeableness; the mixed cluster was the most deviant on almost all aspects. Tabak and Weisman de Mamani (2013) focused on well-being outcomes: the high positive cluster presented similar levels of well-being as the average and low schizotypy profiles; the high negative/disorganized profile had the lowest level of well-being.

The observation that high positive schizotypy clusters tended to display less impairment than the other clusters with significant schizotypy symptoms were consistent with the concept of "healthy schizotypy", characterized by the presence of positive schizotypy symptoms in the absence of negative or dizorganized schizotypy symptoms and mental health problems (e.g., McCreery and Claridge, 2002). Moreover "healthy schizotypy" may be associated with adaptive traits and favourable functioning such as subjective wellbeing, flexible/unconventional thinking and creativity, fantasy-proneness and openness to experience, raising the question of the evolutionary advantages of schizotypy (Morh and Claridge, 2015). However, several studies reported associations between positive schizotypy and mood disorders, substance abuse, and the need for psychiatric treatment (e.g., BarrantesVidal et al., 2010; Chapman et al., 1994; Dinn et al., 2002; van Os and Linscott, 2012). Barrantes-Vidal et al. (2010) found that the positive schizotypy group scored high on neuroticism, frequency of alcohol and substance use and impairment while Dinn et al. 
observed a positive relation between impulsivity, antisocial behaviors and positive schizotypy. Further studies are needed to explore the adaptive and maladaptive correlates of positive shizotypy.

The first aim of the present study was to explore the typology of schizotypal traits in a large nonclinical sample of young adults. We expected to find the three clusters identified by most previous studies (low, high positive, and mixed schizotypy clusters). The second aim was to examine the validity of empirically derived clusters by comparing them with external correlates. We selected depressive symptoms, frequency of cannabis use, social relationships and scholastic impairment, as Barrantes-Vidal et al. (2010) found history of major depressive episodes, drug use and impaired social adjustment to distinguish schizotypy clusters. Based on the findings from correlational studies (as no schizotypy cluster study has addressed this issue), we chose psychopathological symptoms and personality traits that have been reported to be associated to schizotypy - obsessive-compulsive symptoms and disorder traits (Melca et al., 2015), borderline personality disorder traits (Fonseca-Pedrero et al., 2012), autistic traits (Claridge and McDonald, 2009) - postulating that these symptoms and traits could be differentially associated to schizotypy clusters. For example, an association was expected between the positive schizotypy cluster and borderline traits (Chabrol et al., 2002) or autistic traits (Claridge and McDonald, 2009). The last objective was to investigate whether a positive schizotypy group would emerge and to examine its association with social relationships, academic performance, psychopathological symptoms and personality disorder traits, extending the current literature on positive schizotypy correlates. Consistent with previous cluster studies, it was expected that the cluster high on both positive and negative schizotypy would have the highest levels of psychopathological symptoms and personality disorder traits and that the cluster high only on positive schizotypy would show a mixed pattern of positive 
(well-being) and negative (personality disorder traits and psychopathological symptoms) correlates.

2. Materials and methods

\subsection{Participants}

Potential participants were informed about the study via social networks and the official websites of several French universities and invited to participate in a study exploring their behaviors and life habits. Informed consent was obtained from all participants by ticking a box on the Internet website before completing the study. Potential participants were provided with information regarding the aims of the study and were informed that answers to the questionnaires would remain strictly confidential and be analyzed according to scientific intentions. No compensation was offered to participate in the study, following a standard procedure of the institution. However, the participants were provided with the possibility to contact the principal investigator (PR) via email for further information or to receive referral. During the enrolment period (November 2014 to April 2015), 466 individuals (378 females [81.1\%], 88 males [18.9\%]) aged between 18 and 24 (mean age of females $=20.59 \pm 1.71$; males $=20.51 \pm 1.94)$ completed the questionnaire. Only those who answered $>95 \%$ of the items were included in this study, which led to the exclusion of 6 cases. For questionnaires filled out by these 6 individuals, we controled using t-test that there was no significant differences in the sample total scores including or not these 6 cases. The study followed the ethical guidelines of the Helsinki Declaration and its procedures were approved by the ethics committee of the research ward.

\subsection{Measures}

\subsubsection{Personal information}


Personal information (e.g., age, gender) was gathered. Academic results were also measured by asking students their overall grade for the last semester.

\subsubsection{Personality traits}

\subsubsection{Schizotypal traits}

Schizotypal traits were assessed using the Schizotypal Personality Questionnaire-Brief (SPQ-B), a self-administered scale including 22 dichotomous items (Raine and Benishay, 1995). Seeing as no validated French version of this scale exists, translation and backtranslation were conducted by authors who were fluent in both languages. Two translations were made and compared. Discrepancies in the translation process were noted and resolved in a discussion between the translators during a research meeting involving the four authors and two additional people who were also fluent (a researcher and a postdoctoral fellow), both working in Psychology and not directly involved in the study. The three following dimensions of schizotypal personality are assessed: cognitive-perceptual deficits ("Positive"; 8 items), interpersonal deficits ("Negative"; 8 items) and disorganisation (6 items). Each item (e.g., "People sometimes find me aloof and distant") is scored 0/1 (no/yes). A high score is an indicator of elevated schizotypal traits. In this study Cronbach's alpha for SPQ-B was 0.78 , which is in the 0.72-0.80 range reported in other studies (Raine and Benishay, 1995; Axelrod et al., 2001). Cronbach's alpha for SPQ-B factors ranged from 0.56 to 0.83 (Table 1), an acceptable level of consistency (Schmitt, 1996). We also calculated mean interitem correlations (MIC), which does not depend on the number of items. MIC appeared superior (or equal) to .15, which is a satisfactory level of homogeneity (Briggs and Cheek, 1986).

\subsubsection{Autistic traits}

Autistic traits were measured using the 10-item version of the Autism spectrum Quotient (AQ; Baron-Cohen et al., 2001; Booth et al., 2013). A French version of AQ-10 was adapted from the French version of AQ by selecting the 10 relevant items that have been 
selected in AQ-10 (Booth et al., 2013). Items (e.g., "When I am reading a story, I find it difficult to work out the characters intentions") were scored 0 (no) or 1 (yes), except for items 2-6 and 9 that were scored inversely. A high score is an indicator of a high level of autistic traits. Cronbach's alpha was 0.53 , representing an acceptable level of consistency (Schmitt, 1996).

\subsubsection{Borderline personality traits}

Borderline traits were assessed using the nine items of the Personality Diagnostic Questionnaire-4 assessing borderline personality disorder (Hyler et al., 1988). The French version of this questionnaire was found in Bouvard (2002). Items (e.g., "I often question my personal identity and frequently change my opinion of who I am") were scored from 1 (totally false) to 7 (totally true). A high score is indicative of a high level of borderline traits. In this study Cronbach's alpha was 0.82 , which was higher than the 0.69 found in a prior study (Chabrol et al., 2012).

\subsubsection{Obsessional personality traits}

Obsessional traits were measured using the French version of the obsessional personality disorder scale of the Personality Diagnostic Questionnaire-4 (Hyler et al., 1988). The French version of this questionnaire was found in Bouvard (2002). This scale contains 8 items (e.g., "I feel that my standards and ethics are higher than those of my peers") scored 0 (false) or 1 (true). A high score is an indicator of high level of obsessional traits. In this study Cronbach's alpha was 0.58 , which was within the $0.46-0.66$ range found in former studies (Bouvard, 2002; Hyler et al., 1988), representing an acceptable level of consistency for short scales (Schmitt, 1996).

\subsubsection{Psychopathological symptoms}

\subsubsection{Depressive symptoms and suicidal ideations}


Depressive symptoms were assessed using the 10-item version of the Centre for Epidemiological Studies-Depression scale (CES-D; Radloff, 1977) (e.g., "My sleep has not been good"). The French version of this questionnaire was used (Fuhrer and Rouillon, 1989). Responses are rated on a 4-point Likert scale, ranging from 0 to 3. A high score on this scale is indicative of significant depressive symptoms. In this study Cronbach's alpha was 0.69 , which was close to the 0.70 reported by Radloff.

The suicidal ideation was assessed using the 3-item scale proposed by Garrison et al. (1991) ("I felt life was not worth living"; "I felt like hurting myself"; "I felt like killing myself"). A French version of this scale was already described (Chabrol et al., 2007). Responses to these items were made on the same scale as the CES-D items. A suicidal ideation score (range 0-9) was calculated by summing responses on these three items. In this study Cronbach's alpha was 0.82 , close to the 0.85 found in an earlier report (Chabrol et al., 2007).

\subsubsection{Obsessive-compulsive symptoms}

Obsessive-compulsive symptoms were assessed using the Obsessive Compulsive Inventory-Revised (OCI-R) (Foa et al., 2002). The French version of this questionnaire was found in Zermatten et al. (2006). It contains 18 items (e.g., "I check things more often than necessary") scored from 0 ("Not at all") to 4 ("Extremely"). A high score is an indicator of significant obsessive-compulsive symptoms. Cronbach's alpha was 0.85 in this study, which was within the 0.81-0.93 range reported in Foa et al. (2002).

\subsubsection{Frequency of cannabis use}

Frequency of cannabis use was measured using the Cannabis Use Disorder Identification Test-Revised (CUDIT-R), a self-report questionnaire evaluating the frequency of cannabis use over the past 6 months and identifying problematic or harmful cannabis use (Adamson et al., 2010). The French version of this questionnaire was found in Annaheim et 
al. (2008). It contains 8 items (e.g., "How often do you use cannabis?") scored from 0 ("Never") to 4 ("At least four times a week"). A high score suggests a problematic use of cannabis. In the present study, Cronbach's alpha was 0.89 , which was above the 0.84 observed in Adamson et al. (2010).

\subsubsection{Interpersonal relationships}

The quality of interpersonal relationships was measured using the French version of the Quality of Interpersonal Relationship Scale (QIRS; Senecal et al., 1992). This scale is composed of 20 items (e.g., "Presently my relationships with my family are satisfying") scored from 0 ("Not at all") to 4 ("Extremely"). A low score is indicative of poor interpersonal relationships. Cronbach's alpha was 0.80 in this study, close to values already reported (Senecal et al., 1992).

\subsection{Statistical analysis}

Statistical analyses were performed using Statistica 10.

\section{Results}

\subsection{Factor analysis}

A confirmatory factor analysis (CFA) was used to test the Raine and Benishay's 3factor model. Multiple fit indices were used to evaluate the model fully. We chose indices recommended by Tabachnick and Fidell (2007): 1) the model chi square divided by the degree of freedom ( $\chi^{2}$ / df; this value should be smaller than 2.00; the lower this value is, the better the fit), 2) the Goodness-of-Fit Index (GFI; this value should be 0.90 or higher for a good fit; the higher this value is, the better the fit), 3) the Root Mean Square Residual (RMR; this value should be 0.05 or lower; the lower this value is, the better the fit), 4) the Root Mean Square Error of Approximation (RMSEA; this value should be 0.08 or lower; the lower this value is, the better the fit), 5) the Akaike information criterion (AIC, the lower this value is, 
the better the fit). The Raine and Benishay's 3-factor model of the SPQ-B fitted the data poorly $\left(\chi^{2} / \mathrm{df}=3.35, \mathrm{GFI}=0.88, \mathrm{RMR}=0.067, \mathrm{RMSEA}=0.075, \mathrm{AIC}=1.43\right)$. A principal component analysis using an Equamax rotation which is the most adequate rotation method for dichotomous data (Finch, 2011) was conducted on the 22 SPQ-B items to identify a more relevant model based on two criteria: the scree test and the total proportion of variance accounted for (O'Rourke and Hatcher, 2013). The eigenvalue curve suggested either a 2-, 3-, or 4-factor solution. The 2- and 3-factor solutions were deleted because they accounted for an unacceptably low proportion of the total variance ( $28 \%$ and $35 \%$, respectively). The 4 -factor solution accounted for $41 \%$ of the total variance. Each item was assigned to one of the factors if this item loaded greater than 0.30 on that factor and if there was a difference of at least 0.20 between the loading of this item for this factor and the loading of this item for any other factors (Table 2). The factors were called "Negative schizotypy" (5 items, e.g., "people find me aloof and distant"), "Positive schizotypy" (5 items, e.g., "sense some person or force"), "Social anxiety" (2 items, e.g., "very uneasy talking to people"), "Reference ideas" (3 items, e.g., "often pick up hidden threats"). Factors were weakly correlated, with r varying from .06 to .35. As the total amount of the variance accounted for was not high, a CFA was conducted to test the fit of the 4-factor model which showed good fit indices $\left(\chi^{2} / \mathrm{df}=1.69, \mathrm{GFI}=0.96\right.$, $\mathrm{RMR}=0.047, \mathrm{RMSEA}=0.04, \mathrm{AIC}=0.46)$.

\subsection{Cluster analysis}

Cluster analysis was conducted in two steps to generate profiles based on the four factors of schizotypy (positive, negative, social anxiety and reference ideas) converted to zscores. Absence of multicollinearity was evaluated through the correlations between the variables selected for the cluster analysis (all variables had tolerance values $>0.40$ ). In the first step, a hierarchical cluster analysis was conducted (Ward's method with squared Euclidean distance). Based on the dendrogram and the aggregation curve, a four-cluster 
solution was identified. In the second step, K-means clustering was used to assign individuals to one of the identified clusters. A discriminant analysis showed clear differences between clusters (Wilks' $\lambda=0.336, p<0.001$ ) with $96.2 \%$ of cases correctly classified.

Data revealed a first group with means scores on all schizotypy dimensions that were at least greater than half SD above the overall sample means (Figure 1; Table 1). This cluster was thus termed "High schizotypy" (n=98 [21\%], women 77.5\%, men 22.5\%). A second group was characterized with mean scores on all schizotypy factors below the sample means by at least half SD. It was thus called "Low (non schizotypy)" cluster ( $\mathrm{n}=151$ [32\%], women $82 \%$, men $18 \%$ ). A third cluster was characterized with mean score of positive schizotypy greater than the sample mean by nearly one $\mathrm{SD}$, and with scores below the sample means for all other schizotypy dimensions. It was thus named "Positive schizotypy" cluster ( $n=107$ [23\%], women $78.5 \%$, men $21.5 \%$ ). The last cluster had a mean social anxiety score higher than the sample mean by more than one SD, and a mean score for negative schizotypy above the sample mean, while mean scores for positive schizotypy and reference ideas were below the sample means. It was thus termed "Social impairment" ( $n=110$ [24\%], women 82\%, men $18 \%)$. There were no significant differences in the proportions of males and females between clusters and the total sample ( $p=.49, .78, .55, .81$, respectively).

Using one-way analysis of variance, clusters were compared on levels of personality disorder traits (i.e. borderline, obsessional and autistic), psychopathological variables (depression, suicidal ideas, obsessive-compulsive symptoms), cannabis use, interpersonal relations and academic results (Table 1). We used Tukey's HSD which corrects for familywise type I error rate. Compared with all other clusters, the "High" cluster showed higher levels on any personality disorder traits or psychopathological variables assessed in this study, including borderline traits, obsessional traits, autistic traits, depressive symptoms, suicidal ideas and obsessive-compulsive symptoms. 
In addition, the "Positive" and "Social impairment" clusters displayed greater scores, in comparison with the "Low" cluster, on all personality disorder traits or psychopathological variables, except for autistic traits which were not statistically different between "Low" and "Social impairment" or "Positive". The differing variables between "Low" and "Positive" or "Social impairment" thus included: borderline traits, obsessional traits, depressive symptoms, suicidal ideas and obsessive-compulsive symptoms. Regarding interpersonal relations, the "High" and "Social impairment" clusters showed low scores compared with "Low" or "Positive". Academic results differed only between "Low" and "Positive" or "Social impairment". No significant difference between clusters was observed in the frequency of cannabis use.

\section{Discussion}

Cluster analysis based on dimensions of schizotypy symptoms yielded by factor analysis was used to identify an empirically derived typology of young adults in a non-clinical sample. While most previous studies have forced a four-cluster solution, we used an exploratory method to identify the most suitable cluster solution: a hierarchical cluster analysis extracted a four-cluster solution characterized by the following groups: "Low" (non schizotypy), "High schizotypy" (mixed positive and negative), "Positive schizotypy", and "Social impairment", which is thus consistent with prior findings (Barrantes-Vidal et al., 2010; Suhr and Spitznagel, 2001).

In line with the main study exploring the association between schizotypy cluster and psychopathology (Barrantes-Vidal et al., 2010), the "High schizotypy" cluster showed the greatest association with psychopathology. The "High schizotypy" cluster scored higher on borderline and obsessional personality traits than the "Positive" and the "Social impairment" 
clusters, which scored higher than the "Low schizotypy" cluster. Concerning autistic traits, the "High schizotypy" cluster scored higher than the "Positive" and "Low schizotypy" clusters. Similarly, the "High schizotypy" cluster scored higher on depressive symptoms, suicidal ideations, and obsessive-compulsive symptoms than the "Positive" and the "Social impairment" clusters, which both scored higher than the "Low schizotypy" cluster. There were no significant differences between the "Social impairment" and the "Positive" clusters on all symptoms. This result is in accordance with Horan et al.'s study (2013) which also found no difference between the negative and positive schizotypy groups on negative affectivity.

In line with prior studies, our "Positive" group characterized by above average scores on unusual experiences, odd beliefs, and magical thinking and below average scores on all other dimensions, was similar to the "high unusual experience group" found by Tabak and Weisman de Mamani (2013). This "Positive" group was not associated with significantly higher levels of borderline personality disorder traits or cannabis use which may have contributed to explain the positive symptoms. This suggested that positive schizotypy symptoms did not reflect effects of cannabis use or dissociation (a defense mechanism associated to borderline traits), that both may mimic some positive schizotypal symptoms such as cognitive or perceptual distortions. So, this pure positive schizotypy group, independent from borderline traits and cannabis use, was ideal to explore the psychopathogical correlates of positive schizotypy.

Our Positive schizotypy group had higher levels of personality disorder traits and psychopathological symptoms than the "Low" (non schizotypy) cluster, but did not differ from the "Social impairment" cluster on theses variables. Regarding psychosocial functioning, the "Positive" cluster showed contrasting results. It displayed the lowest level of academic achievement but quality of interpersonal relationships was not different from the "Low 
schizotypy" cluster, and was higher than that observed in the "High schizotypy" and the "Social impairment" clusters. Interestingly, while our study yielded a pure positive schizotypy cluster, this group was characterized by high levels of psychopathological symptoms, personality disorder traits, and low academic achievement. However, despite these difficulties, this group reported a quality of interpersonal relationships similar to that observed in the non-schizotypy group. This result is in line with those of Horan et al. (2013) and Tabak and Weisman de Mamani (2013) which found levels of satisfaction with social supports and positive relations to others in the positive schizotypy group comparable to the control (nonschizotypy) group. So, our study challenges the concept of healthy schizotypy. Our results suggest that, although positive schizotypy may be associated to some benefits such as perceived positive quality of social relationships, it is also associated to high levels of personality disorder traits and psychopathological symptoms and low academic achievement that were similar to that observed in the "Social impairment" cluster. As a consequence, positive schizotypy may have a clearly unhealthy side. Moreover, given that positive schizotypy is associated to high levels of borderline, autistic and obsessional personality traits, which all have negative effects on interpersonal relationships, it may be possible that normal levels of satisfaction with social supports and perceived positive relations reflect either lack of insight, as suggested by Tabak and Weisman de Mamani, and/or the tendency to deform reality and adapt it to one's own wishes, which is associated to magical thinking, a key component of positive schizotypy. Other advantages attributed to positive schizotypy, such as subjective well-being, may also be linked to lack of insight and wishful thinking. This possibility suggests to measure potential benefits of positive schizotypy using methods that are more objective and less sensitive to wishful thinking.

This study has several limitations. This study should be considered as exploratory and descriptive. Results are data-driven and may be not generalizable. In addition, this study was 
cross-sectional, which excluded the exploration of causal interactions and did not allow to determine whether the identified profiles are stable over time or whether individuals may switch from one group to the other, based on life events or other factors that may promote psychosis (substance use, stressful life experiences...) (Tabak and Weisman de Mamani, 2013). Another limitation of this study is the fact that scales showed suboptimal Cronbach's alphas, ranging between 0.50 and 0.70 . Although this is considered as an acceptable level of consistency (Schmitt, 1996), alternative measures with more acceptable levels of internal consistency should be employed in further studies.

However, our study indicates the interest of studying the personality disorder and psychopathological correlates of schizotypy clusters. It also provides support in favor of the existence of a group of individuals with pure positive schizotypy and suggests that positive schizotypy, the potential benefits of which have recently been highlighted (Morh and Claridge, 2015), may have an unhealthy side.

Conflict of interest: The authors do not have conflict of interest.

Author contributions: PR, NG, VN and HC participated in the design of the study. HC conducted the statistical analysis and wrote the first draft of the manuscript. PR, NG, VN and $\mathrm{HC}$ contributed to manuscript writing and approved the final manuscript.

\section{References}

Adamson, S. J., Kay-Lambkin, F. J., Baker, A. L., Lewin, T. J., Thornton, L., Kelly, B.J., Sellman, J.D., 2010. An improved brief measure of cannabis misuse: The Cannabis Use Disorders Identification Test-Revised (CUDIT-R). Drug Alcohol Depend. 110, 137-143. Annaheim, B., Rehm, J., Gmel, G., 2008. How to screen for problematic cannabis use in population surveys. An evaluation of the Cannabis Use Disorders Identification Test 
(CUDIT) in a Swiss sample of adolescents and young adults. Europ. Addict. Res., 14, 190197.

Axelrod, S. R., Grilo, C. M., Sanislow, C., McGlashan, T. H., 2001. Schizotypal Personality Questionnaire-Brief: Factor structure and convergent validity in inpatient adolescents. J. Pers. Disord. 15, 168-179.

Baron-Cohen, S., Wheelwright, S., Skinner, R., Martin, J., Clubley, E., 2001. The autismspectrum quotient (AQ): Evidence from Asperger Syndrome/high-functioning autism, males and females, scientists and mathematicians. J. Autism Dev. Disord. 31, 603-603.

Barrantes-Vidal, N., Fañanás, L., Rosa, A., Caparrós, B., Riba, M. D., Obiols, J. E., 2003. Neurocognitive, behavioural and neurodevelopmental correlates of schizotypy clusters in adolescents from the general population. Schizophr. Res., 61, 293-302.

Barrantes-Vidal, N., Lewandowski, K. E., Kwapil, T. R., 2010. Psychopathology, social adjustment and personality correlates of schizotypy clusters in a large nonclinical sample. Schizophr. Res. 122, 219-225.

Booth, T., Murray, A. L., McKenzie, K., Kuenssberg, R., O'Donnell, M., Burnett, H., 2013. Brief report: An evaluation of the AQ-10 as a brief screening instrument for ASD in adults. J. Autism Dev. Disord. 43, 2997-3000.

Bouvard, M., 2002. Questionnaires et échelles d'évaluation de la personnalité. Masson. Paris.

Briggs, S. R., and Cheek, J. M., 1986. The role of factor-analysis in the development and evaluation of personality-scales. J. Pers. 54, 106-148.

Chabrol, H., Montovany, A., Callahan, S., Chouicha, K., Ducongé, E., 2002. Factor analyses of the DIB-R in adolescents. J. Pers. Disord., 16, 374-384.)

Chabrol, H., Rodgers, R., Rousseau, A., 2007. Relations between suicidal ideation and dimensions of depressive symptoms in high-school students. J. Adolescence 30, 587-600.

Chabrol, H., Valls, M., van Leeuwen, N., Bui, E., 2012. Callous-unemotional and borderline traits in nonclinical adolescents: Personality profiles and relations to antisocial behaviors. Pers. Indiv. Differ. 53, 969-973.

Claridge, G., McDonald, A., 2009. An investigation into the relationships between convergent and divergent thinking, schizotypy, and autistic traits. Pers. Indiv. Differ. 46, 794-799.

Dinn, W. M., Harris, C. L., Aycicegi, A., Greene, P., Andover, M. S., 2002. Positive and negative schizotypy in a student sample: neurocognitive and clinical correlates. Schizophr. Res. 56, 171-185.

Finch, W. H., 2011. A comparison of factor rotation methods for dichotomous data. J. Mod. Appl. Stat. Meth. 10, 549-570. 
Foa, E. B., Huppert, J. D., Leiberg, S., Langner, R., Kichic, R., G. Hajcak, Salkovskis, M. 2002. The obsessive-compulsive inventory: Development and validation of a short version. Psychol. Assessment 14, 485-496.

Fonseca-Pedrero, E., Lemos-Giraldez, S., Paino, M., Sierra-Baigrie, S., Muniz, J., 2012. Relationship between schizotypal and borderline traits in college students. Span. J. Psychol. 15, 306-314.

Fuhrer, R., Rouillon, F., 1989. The French version of the Center for Epidemiologic StudiesDepression Scale. Psychiatr. Psychobiol., 4,163-166.

Garrison, C. Z., Addy, C. L., Jackson, K. L., McKeown, R. E., Waller, J. L., 1991. A longitudinal study of suicidal ideation in young adolescents. J. Am. Acad. Child Adolesc. Psychiatry, 30, 597-603.

Gross, G. M., Silvia, P. J., Barrantes-Vidal, N., Kwapil, T. R., 2015. The dimensional structure of short forms of the Wisconsin Schizotypy Scales. Schizophr. Res. 166, 80-85.

Horan, W. P., Brown, S. A., Blanchard, J. J., 2007. Social anhedonia and schizotypy: the contribution of individual differences in affective traits, stress, and coping. Psychiat. Res. $149,147-156$.

Hyler, S. E., Rieder, R. O., Williams, J. B., Spitzer, J. H., Lyons, M., 1988. The Personality Diagnostic Questionnaire: Development and preliminary results. J. Pers. Disord. 2, 229237.

Kocsis-Bogár, K., Nemes, Z., Perczel-Forintos, D., 2016. Factorial structure of the Hungarian version of Oxford-Liverpool Inventory of Feelings and Experiences and its applicability on the schizophrenia-schizotypy continuum. Pers. Indiv. Differ. 90, 130-136.

Kwapil, T. R., Gross, G. M., Silvia, P. J., Barrantes-Vidal, N., 2013. Prediction of psychopathology and functional impairment by positive and negative schizotypy in the Chapmans' ten-year longitudinal study. J. Abnorn. Psychol. 122, 807-815.

McCreery, C., Claridge, G., 2002 Healthy schizotypy: the case of out-of-the-body experiences. Pers. Indiv. Differ. 32, 141-154.

Melca, I. A., Yucel, M., Mendlowicz, M. V., de Oliveira-Souza, R., Fontenelle, L. F., 2015. The correlates of obsessive-compulsive, schizotypal, and borderline personality disorders in obsessive-compulsive disorder. J. Anxiety Disord. 33, 15-24.

Mohr, C., Claridge, G., 2015. Schizotypy-Do not worry, it is not all worrisome. Schizophr. Bull. 41, S436-S443.

O'Rourke, N., Hatcher, L., 2013. A step-by-step approach to using SAS for factor analysis and structural equation modeling. Sas Institute. 
Radloff, L. S., 1977. The CES-D Scale: A self-report depression scale for research in the general population. Appl. Psych. Meas. 1, 385-401.

Raine, A., Benishay, D., 1995. The SBQ-B: A brief screening instrument for schizotypal personality disorder. J. Pers. Disord. 9, 346-355.

Saunders, J. B., Aasland, O. G., Babor, T. F., Delafuente, J. R., Grant, M., 1993. Development of the Alcohol-Use Disorders Identification Test (AUDIT) - WHO collaborative project on early detection of persons with harmful alcohol-consumption. Addiction 88, 791-804.

Schmitt, N., 1996. Uses and abuses of coefficient alpha. Psychol. Assessment 8, 350-353.

Senecal, C. B., Vallerand, R. J., Vallieres, E. F., 1992. Construction et validation de l'échelle de la qualité des relations interpersonnelles (EQRI). Eur. Rev. Appl. Psychol. 42, 315-322.

Spielberger, C. D., 1988. Manuel for the state-trait anger expression inventory (STAXI): PAR 2000.

Suhr, J. A., Spitznagel, M. B., 2001. Factor versus cluster models of schizotypal traits. I: A comparison of unselected and highly schizotypal samples. Schizophr. Res. 52, 231-239.

Tabachnick, B. G., Fidell, L. S., 2007. Using multivariate statistics, $5^{\text {th }}$. Needham Height, MA: Allyn and Bacon.

Tabak, N. T., Weisman de Mamani, A. G., 2013. Latent profile analysis of healthy schizotypy within the extended psychosis phenotype. Psychiat. Res. 210, 1008-1013.

van Os, J., Linscott, R. J., 2012. Introduction: the extended psychosis phenotypeRelationship with schizophrenia and with ultrahigh risk status for psychosis. Schizophr. Bull. 38, 227-230.

Williams, L. M., 1994. The multidimensional nature of schizotypal traits: a cluster analytic study. Pers. Indiv. Differ., 16, 103-112.

Zermatten, A., Van der Linden, M., Jermann, F., Ceschl, G., 2006. Validation of a French version of the Obsessive-Compulsive Inventory-Revised in a non-clinical sample. Eur. Rev. Appl. Psychol. 56, 151-155. 


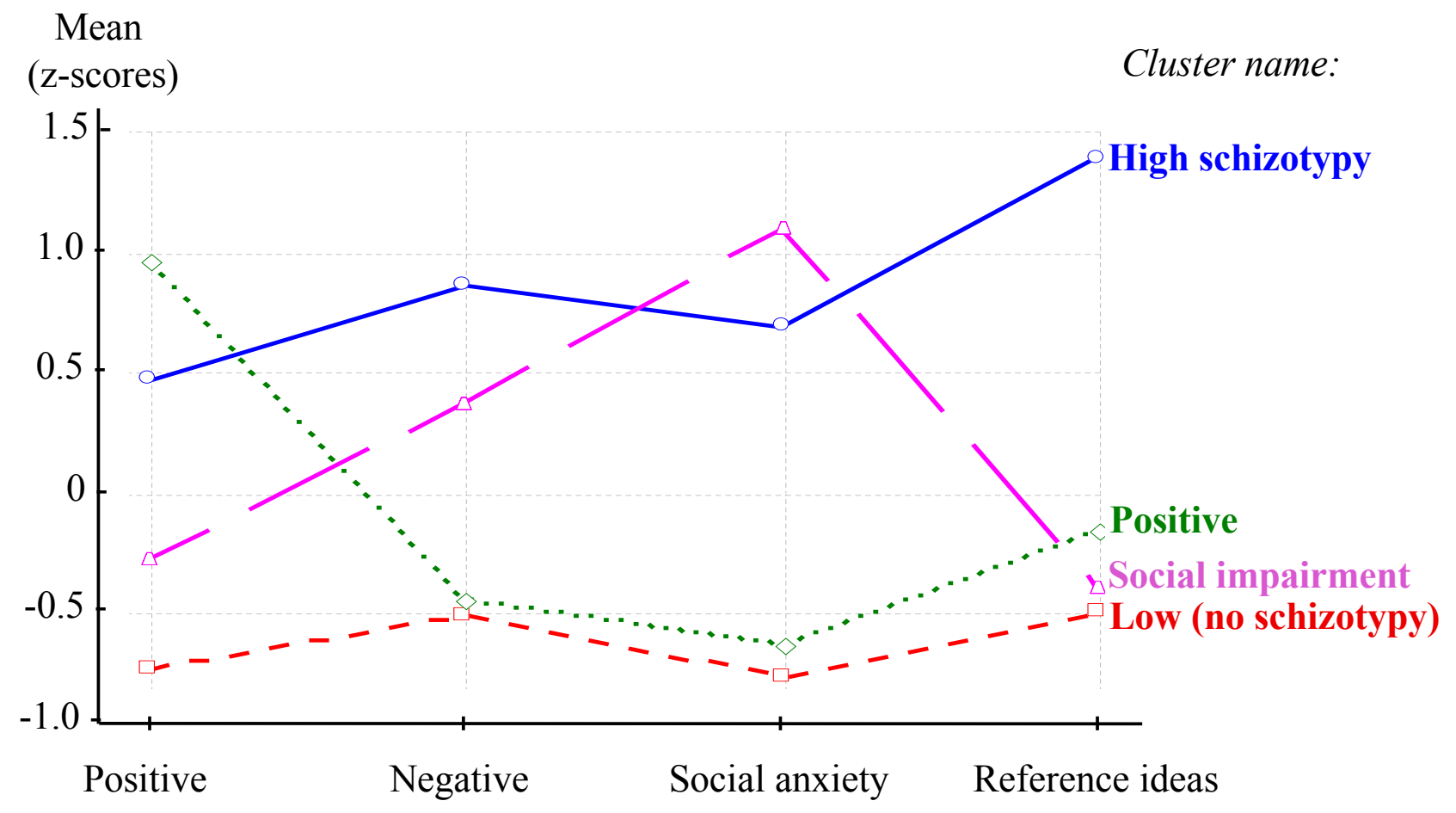

Figure 1. Four-cluster solution based on four factors of schizotypal personality indicated on the $\mathrm{x}$-axis. 
Table 1

Typology of individuals on four dimensions of schizotypy. Cluster comparison using ANOVA and post-hoc test.

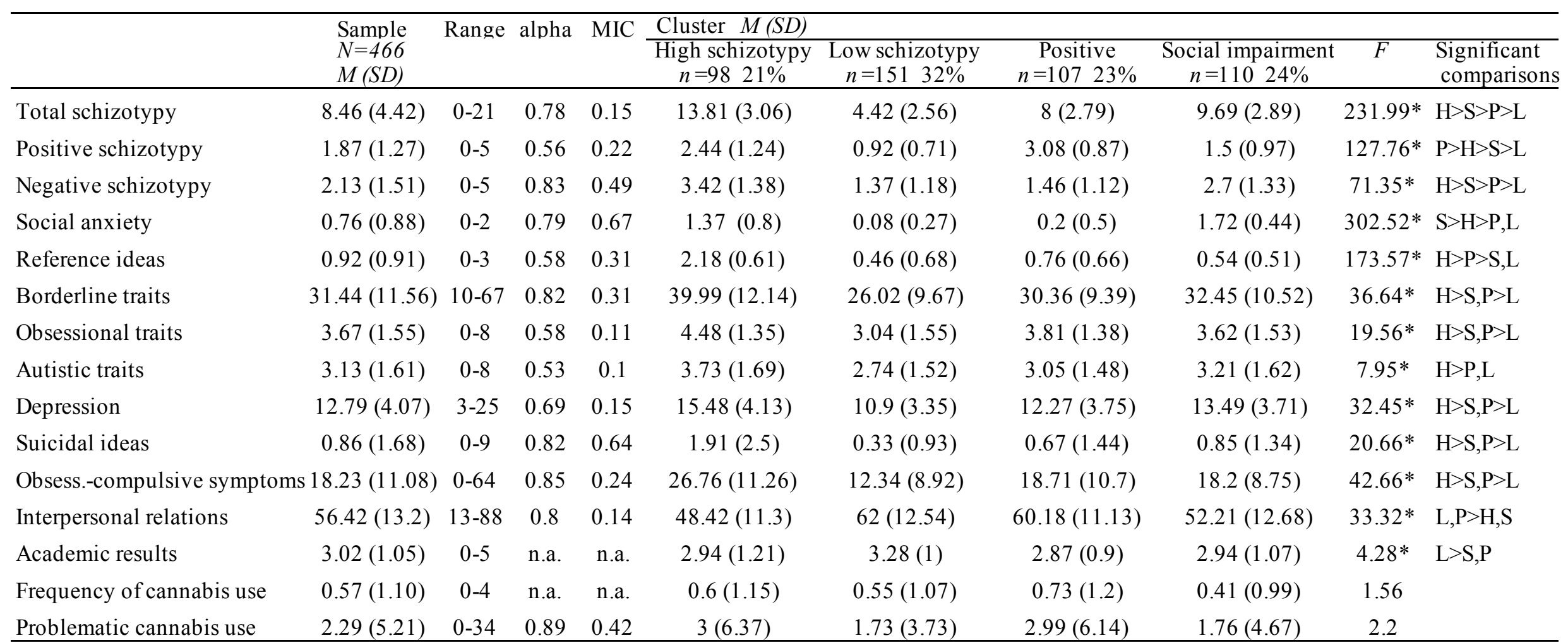

MIC: mean interitem correlation; n.a.: not applicable ; ${ }^{*}<<0.05$

L, "Low schizotypy" cluster; H, "High schizotypy" cluster; P, "Positive schizotypy" cluster; S, "Social impairment" cluster 
Table 2

Principal component analysis of 22 SPQ-B items

\begin{tabular}{|c|c|c|c|c|}
\hline \multirow[b]{2}{*}{ item } & \multicolumn{4}{|c|}{ Factor loadings } \\
\hline & $\begin{array}{c}1 \\
\text { Negative } \\
\text { schizotypy }\end{array}$ & $\begin{array}{c}2 \\
\text { Positive } \\
\text { schizotypy }\end{array}$ & $\begin{array}{c}3 \\
\text { Social } \\
\text { anxiety }\end{array}$ & $\begin{array}{c}4 \\
\text { Reference } \\
\text { ideas }\end{array}$ \\
\hline 1. people find me aloof and distant & $\underline{0.64}$ & 0.05 & 0.2 & -0.28 \\
\hline 2. sense some person or force & $\overline{-0.1}$ & $\underline{0.59}$ & 0.06 & -0.15 \\
\hline 3. unusual mannerisms and habits & 0.43 & 0.42 & -0.23 & -0.01 \\
\hline 4. people can tell what you're thinking & -0.19 & $\underline{0.45}$ & 0.15 & 0.2 \\
\hline 5. noticed special signs for you & 0.03 & $\overline{\mathbf{0 . 4 6}}$ & -0.15 & 0.2 \\
\hline 6. people think I am very bizarre & $\underline{0.63}$ & 0.29 & 0.03 & 0.03 \\
\hline 7. on my guard even with friends & 0.55 & -0.07 & -0.05 & 0.37 \\
\hline 8. people find me vague and elusive & 0.26 & 0.32 & 0.12 & 0.14 \\
\hline 9. often pick up hidden threats & 0.26 & 0.02 & -0.01 & $\underline{0.59}$ \\
\hline 10. people are taking notice of you & 0.07 & 0.18 & 0.03 & $\underline{0.43}$ \\
\hline 11. discomfort with unfamiliar people & 0.29 & 0.04 & $\underline{0.77}$ & 0.16 \\
\hline 12. astrology, UFOs, ESP, sixth sense & 0.19 & $\underline{0.48}$ & $\overline{-0.17}$ & -0.05 \\
\hline 13. I use words in unusual ways & -0.01 & $\overline{\mathbf{0 . 4 2}}$ & 0.13 & 0.09 \\
\hline 14. not let people know about you & $\underline{0.61}$ & -0.06 & -0.05 & 0.2 \\
\hline 15. tend to keep in the background & 0.6 & -0.08 & 0.44 & 0.01 \\
\hline 16. distracted by distant sounds & 0.17 & 0.4 & 0.12 & 0.47 \\
\hline 17. stops people from taking advantage & 0.15 & 0.06 & 0.1 & $\underline{0.68}$ \\
\hline 18. unable to get "close" to people & $\underline{0.59}$ & -0.05 & 0.08 & 0.22 \\
\hline 19. I am an odd, unusual person & 0.45 & 0.39 & -0.23 & 0.01 \\
\hline 20. hard to communicate clearly & 0.45 & 0.29 & 0.29 & 0.08 \\
\hline 21. very uneasy talking to people & 0.23 & 0.05 & $\underline{0.82}$ & 0.05 \\
\hline 22. tend to keep my feelings to myself & $\underline{0.44}$ & -0.1 & 0.08 & 0.03 \\
\hline Eigenvalues & $\overline{4.28}$ & 1.92 & 1.45 & 1.30 \\
\hline Explained variance & $15 \%$ & $9 \%$ & $9 \%$ & $8 \%$ \\
\hline
\end{tabular}

Values $>0.3$ are in bold

Items retained in the model are underlined 